\title{
Proximal Muscle Weakness in a Child with Kawasaki Disease
}

\author{
Sikha Agarwal • Anju Gupta • Deepti Suri • Amit Rawat • \\ Surjit Singh
}

Received: 10 October 2014 / Accepted: 21 January 2015 /Published online: 15 February 2015

(C) Dr. K C Chaudhuri Foundation 2015

To the Editor: Musculoskeletal manifestations in Kawasaki disease $(\mathrm{KD})$ have been occasionally reported, arthritis being the most common. We report a 10 -y-old girl with $\mathrm{KD}$ who developed debilitating proximal muscle weakness in convalescent phase of the disease.

A 10-y-old girl presented with fever for 12d. She developed conjunctival injection along with strawberry tongue and a maculopapular rash three days after fever. Examination showed cervical lymphadenopathy, swelling over dorsum of hands and periungual desquamation. There was swelling of both knee joints. Investigations showed microcytic hypochromic anemia (hemoglobin-71 g/L), elevated erythrocyte sedimentation rate $(62 \mathrm{~mm} 1 \mathrm{st} . \mathrm{h})$ and thrombocytosis $\left(7.73 \times 10^{9} / \mathrm{L}\right)$. C-reactive protein was $66.5 \mathrm{mg} / \mathrm{L}$ and blood culture was sterile. She had normal echocardiogram on admission. With a clinical diagnosis of $\mathrm{KD}$ the child was treated with intravenous immunoglobulin $(2 \mathrm{~g} / \mathrm{kg})$ and aspirin. She became afebrile within a day.

Four weeks later she presented with pain, weakness of hip extensors and difficulty in getting up from squatting position. She was unable to walk because of the pain. The muscle enzymes (aspartate transaminase and total creatine kinase) were, however, within normal limits. She was started on naproxen but had only minimal improvement. In view of her incapacitating

S. Agarwal $\cdot$ A. Gupta $\cdot$ D. Suri $\cdot$ S. Singh $(\triangle)$

Department of Pediatrics, Post Graduate Institute of Medical

Education and Research (PGIMER), Chandigarh 160012, India

e-mail: surjitsinghpgi@rediffmail.com

\section{A. Rawat}

Department of Pathology, Post Graduate Institute of Medical

Education and Research (PGIMER), Chandigarh, India weakness, she was started on prednisolone $(2 \mathrm{mg} / \mathrm{kg} / \mathrm{d})$. Gradually the child regained complete muscle power with normal activity over the next 8-10 wk. An electromyogram was not considered necessary in view of the brisk clinical response. Glucocorticoids were tapered and stopped over $3 \mathrm{mo}$.

Musculoskeletal manifestations are known to occur in KD. Arthritis is described in nearly $15-25 \%$ of cases [1]. Muscle involvement in $\mathrm{KD}$ in form of inflammation or weakness has been described in a few case reports [2,3]. Immune complex deposition in the tissues has been postulated as a triggering mechanism [4]. Usually no specific therapy is required. Our patient had severe and debilitating proximal muscle weakness requiring glucocorticoids for the treatment. This case reiterates the fact that KD is a multisystem disease and can have multiple manifestations. Though there are no specific guidelines for treatment of musculoskeletal manifestation, a short course of glucocorticoids can result in rapid resolution of symptoms.

Conflict of Interest None.

Source of Funding None.

\section{References}

1. Jen M, Brucia LA, Pollock AN, Burnham JM. Cervical spine and temporomandibular joint arthritis in a child with Kawasaki disease. Pediatrics. 2006;118:e1569-71.

2. Gama C, Breeden K, Miller R. Myositis in Kawasaki disease. Pediatr Neurol. 1990;6:135-6.

3. Koutras A. Myositis with Kawasaki's disease. Am J Dis Child. 1982;136:78-9.

4. Hicks JT, Korenyi-Both A, Utsinger PD, Baran EM, McLaughlin GE. Neuromuscular and immunochemical abnormalities in an adult man with Kawasaki disease. Ann Intern Med. 1982;96:607-10. 